\title{
Oral health service delivery in Limpopo Province
}

SADJ August 2017, Vol 72 no 7 p310 - p314

KL Thema', s Singh ${ }^{2}$

\section{ABSTRACT \\ There is little published evidence on the current state of oral health service delivery in Limpopo Province.}

Aim and objectives: To assess oral health service delivery in the public sector in Limpopo Province.

Materials and methods: This is a cross-sectional, explorative and descriptive study using a combination of qualitative and quantitative data to assess oral health service delivery. Data collection included self-administered questionnaires, a face-to-face interview and statistical records on oral health services. Convenience sampling was used to select oral health care workers $(n=84)$ and purposive sampling to select Oral Health District Managers $(n=5)$. An in-depth face- to- face interview was conducted with the Provincial Oral Health Manager.

Results: The most common clinical procedure was dental extractions (ranging from $59 \%$ to $85 \%$ of the total headcount for patient visits in the identified month). Less than a quarter of respondents $(n=19,23 \%)$ indicated that dental resources were adequate and fewer that resources were easily available $(n=17,21 \%)$. Themes arising from data analysis included lack of policy support; no dedicated funding; and poor oral health representation within different levels of the health system.

Conclusion: There is an urgent need for re-orientation of oral health services towards prevention and promotion.

Key words: Oral health services, oral health care workers, dental resources, oral health decision-making.

\section{INTRODUCTION}

Most commonly occurring oral diseases are largely preventable, yet oral health care faces huge challenges in South Africa. The prevalence and distribution of oral

1. Kgaladi Lawrence Thema: Dip Dental Therapy (MEDUNSA), B. Dental Therapy Hons (MEDUNSA), M.Sc Dental Pub Heal (University College London), PhD Health Sciences (UKZN). Discipline of Dentistry, School of Health Sciences, University of KwaZulu-Natal.

2. Shenuka Singh: B.OH (UDW), M.Sc [DENT], PhD (UWC), PG Dip Heal Res Ethics (Stell). Discipline of Dentistry, School of Health Sciences, University of KwaZulu-Natal.

\section{Corresponding author}

Shenuka Singh:

Discipline of Dentistry, School of Health Sciences, University of KwaZuluNatal, Private Bag X54001, Durban, 4000. Tel: 031242 8591,

Fax: 031260 8069. E-mail: singhshen@ukzn.ac.za

\section{ACRONYM}

OHCWs: oral health care workers

diseases are uneven across the various provinces and are poorly documented. ${ }^{1}$ This unclear picture of oral health status is very similar to that describing the public oral health delivery platforms in parts of Africa and in other developing countries..$^{2-5}$ The support for oral health service delivery is dependent on adequate funding; infrastructure; and resources, including the availability of an appropriate mix of oral health skills.,6 The discrepancy in the number and distribution of oral health care workers (OHCWs) across the provinces in South Africa is cause for concern. ${ }^{7}$ According to Statistics South Africa, the highest number of $\mathrm{OHCWs}$ is located in Gauteng (ratio of OHCW per population 1: 6217) with the lowest number being recorded in the Northern Cape (ratio of OHCWs per population 1: 20 070). ${ }^{7}$ Given that the majority of the population is dependent on public oral health services, the availability and quality of oral health services, together with the appropriate skills-mix for oral health service delivery are important considerations for oral health planning.

\section{LIMPOPO PROVINCE}

Limpopo Province is one of the disadvantaged regions of South Africa with limited published data on oral health policy formulation and practice. The National Children's Oral Health Survey 2001-2002 indicated that the Province had the lowest levels of dental caries in children, with only $31.3 \%$ caries prevalence rates in $4-5$ year-olds, and $37.2 \%$ caries prevalence rates in 6-year-old children. ${ }^{8}$ There is insufficient literature on the current state of oral health care in Limpopo Province with regards to service delivery, human resources allocation and policy support for oral health service delivery. This paper then arose out of a need to investigate public oral health service delivery in Limpopo Province. The current Department of Health records suggest that there were 188 dentists, 47 oral hygienists, 57 dental therapists, six dental technicians and 187 dental assistants employed within the public sector in Limpopo province in 2015. Dentists are located in hospitals, oral hygienists are distributed in hospitals and Community Health Centres, while dental therapists are employed in the Community Health Centres in districts of Limpopo Province.

The aim and objectives of this study were to assess oral health service delivery in the public sector in Limpopo Province and to explore the perspectives of oral health care workers on oral health care delivery in the Province. 
The study also aimed to explore oral health decisionmaking in the Province to gain a better understanding of the context of policy planning and implementation.

\section{MATERIALS AND METHODS}

This was a cross-sectional, explorative and descriptive study that used a combination of qualitative and quantitative data to assess oral health service delivery in Limpopo Province. The study site included all five districts of Limpopo Province (Capricorn, Mopani, Sekhukhune, Vhembe and Waterberg). Ethical clearance was obtained from the Biomedical Research Ethics Committee at the University of KwaZulu-Natal (BREC REF: 327/14), and approval to conduct the study was obtained from the Department of Health in Limpopo Province. Permission to recruit participants was obtained from the Chief Executive Officers at the individual hospitals. All ethical considerations such as respect for persons, confidentiality, privacy and anonymity were upheld. Written informed consent was obtained from all participants.

The study used convenience sampling to select oral health care workers (dental assistants, dental therapists, dentists and oral hygienists) $(n=84)$ from amongst those employed in the public sector, and purposive sampling to select Oral Health District Managers in each of the five districts in Limpopo Province $(n=5)$. Dental assistants were included in this study because it was deemed important to ascertain their perspectives on oral health service delivery. All other staff not involved in oral health service delivery were excluded from the study.

Data collection processes included self-administered questionnaires, a face-to-face interview and statistical records on oral health services in the Province. A selfadministered questionnaire was used to collect data from OHCWs. This used both open-ended and closeended questions to gather information on oral health service delivery; perceptions on institutional support for service delivery; evaluation of patient satisfaction in services rendered; impact of health services; challenges in oral health service delivery and recommendations for improved service delivery. A Likert scale format with responses such as 1-strongly disagree 2-disagree 3-not sure 4-agree 5-strongly agree, was used to elicit the perception of respondents to questions such as is the morale of oral health professionals high; are there enough resources, dental equipment and appropriate professionals'; and 'are dental resources easily obtained when a requisition is made?'.

Another self-administered questionnaire was developed and distributed among the five purposively selected District Oral Health Managers to gain a deeper understanding of the organisational structure and delivery of district oral health services; the existence of district policy documents on oral health care; and the strengths and challenges facing oral health services. A similar Likert scale format was used to elicit their perceptions on statements such as 'oral health programs are given priority by the health authorities; and we have sufficient dental equipment and appropriate oral health professionals'. An in-depth face-to-face interview was conducted with the Provincial Oral Health Manager in Limpopo Province. The purpose of the interview was to ascertain Provincial oral health policy planning and implementation; the current state of oral health services; the strengths and limitations of the services provided and the mechanisms provided to improve service delivery.

Available monthly statistical records on oral health services delivery were obtained for the period: November 2015 to March 2016. These retrospective data were recorded on a data capturing sheet and coded and analysed. In most cases, the researchers had access to only one monthly report per institution for this period. To minimise bias, only the first retrieved report was included in the study. Three reports were excluded due to inconsistency in the data that was captured by the health institutions (the total number of services offered did not correspond with total headcount of patients).

Quantitative data were entered on an Excel sheet and imported to the SPSS statistical software (IBM SPSS Statistics Version 23 which was used for data analysis. Univariate descriptive statistics such as frequency and mean distribution were conducted for all variables. A $p$-value of $<0.05$ was set as being significant. The responses to the open-ended questions were grouped and emergent themes were examined and compared for possible associations.

The narrative from the interview transcript was coded and analysed based on the conventional thematic analysis approach. The emergent themes from the interview were compared with the results obtained from the questionnaires and statistical records.

\section{RESULTS}

The study sample $(n=84)$ comprised of 37 dentists, 13 oral hygienists, four dental therapists, 29 dental assistants and one dental technician. The majority of the dentists and dental assistants were located in the Capricorn, Mopani, Sekhukhune districts (an average of nine staff per district). The dental therapists were evenly distributed across the districts. Four of the 13 oral hygienists were located in Capricorn district. Almost $73 \%$ of the respondents were female $(n=61)$.

\section{ORAL HEALTH SERVICE PROVISION (PATIENT VISITS PER FACILITY)}

The available statistical records indicate that at least one facility in each of the districts recorded a monthly patient headcount of more than 500 patient visits (Table 1). Only Waterberg district recorded a headcount of less than 250 patient visits for the identified month. The most common dental clinical procedure was dental extractions (ranging from $59 \%$ to $85 \%$ of the total headcount for patient visits in the identified month). The majority of extractions were of permanent teeth (ranging from $43 \%$ to $80 \%$ of all extractions performed). Restorations accounted for less than $16 \%$ of the total patient headcount, with the exception of Sekhukune district (Facility A), which recorded $30 \%$ of restorations $(n=101)$ done in the identified month. Only Vhembe district (Facility D) recorded a notable number of fissure sealants done $(n=140,39 \%)$. Similarly the highest number of scaling and polishing cases $(n=58$, $12 \%)$ was recorded in Vhembe district (Facility D). Clinical procedures such as removal of impacted teeth, removal of roots, management of dry socket (alveolitis), fractures and screening for oral cancers had low records for the identified month. 


\begin{tabular}{|c|c|c|c|c|c|c|c|c|c|c|c|c|c|c|}
\hline \multirow[t]{2}{*}{ District } & \multirow{2}{*}{$\begin{array}{l}\text { Month } \\
\text { / } \\
\text { Head } \\
\text { Count }\end{array}$} & \multicolumn{3}{|c|}{ Extractions } & \multicolumn{2}{|c|}{ Restorations } & \multirow{2}{*}{$\begin{array}{l}\text { Fissure } \\
\text { sealants } \\
(\%)\end{array}$} & \multirow{2}{*}{$\begin{array}{l}\mathrm{SP} \\
(\%)\end{array}$} & \multirow{2}{*}{$\begin{array}{l}\text { Removal } \\
\text { of } \\
\text { Impacted } \\
\text { teeth (\%) }\end{array}$} & \multirow{2}{*}{$\begin{array}{l}\text { Root } \\
\text { removal } \\
(\%)\end{array}$} & \multirow{2}{*}{$\begin{array}{l}\text { Suturing: } \\
\text { laceration } \\
(\%)\end{array}$} & \multirow{2}{*}{$\begin{array}{l}\text { Dry } \\
\text { Socket } \\
(\%)\end{array}$} & \multirow{2}{*}{$\begin{array}{l}\text { Fractures } \\
(\%)\end{array}$} & \multirow{2}{*}{$\begin{array}{l}\text { Oral } \\
\text { cancer } \\
\text { head } \\
\text { count } \\
(\%)\end{array}$} \\
\hline & & $\begin{array}{l}\text { Perm } \\
\text { teeth (\%) }\end{array}$ & $\begin{array}{l}\text { Primary } \\
\text { Teeth } \\
\text { (\%) }\end{array}$ & $\begin{array}{l}\text { Total } \\
(\%)\end{array}$ & $\begin{array}{l}\text { Amalgam } \\
(\%)\end{array}$ & $\begin{array}{l}\text { Comp } \\
(\%)\end{array}$ & & & & & & & & \\
\hline $\begin{array}{l}\text { Vehembe } \\
\text { Facility A }\end{array}$ & 589 & 401 (68) & $74(13)$ & 475 (81) & $0(0)$ & $0(0)$ & $0(0)$ & $3(0.5)$ & $5(0.8)$ & $6(1)$ & $8(1.4)$ & $6(1)$ & $2(03)$ & $0(0)$ \\
\hline $\begin{array}{l}\text { Vehembe } \\
\text { Facility C }\end{array}$ & 360 & $178(49)$ & $35(8)$ & $213(59)$ & $0(0)$ & $0(0)$ & $140(39)$ & $16(4)$ & $0(0)$ & $0(0)$ & $4(1)$ & $1(0.3)$ & $4(1)$ & $0(0)$ \\
\hline $\begin{array}{l}\text { Vehembe } \\
\text { Facility D }\end{array}$ & 484 & $272(56)$ & $128(26)$ & $400(83)$ & $10(2)$ & $57(12)$ & $26(5)$ & $58(12)$ & $3(0.6)$ & $25(5)$ & $8(2)$ & $6(1)$ & $2(0.4)$ & - \\
\hline $\begin{array}{l}\text { Sekhukune } \\
\text { Facility A }\end{array}$ & 340 & $205(60)$ & $64(19)$ & 269 (79) & $0(0)$ & $101(30)$ & $8(2)$ & $28(8)$ & $0(0)$ & $8(2)$ & $14(4)$ & $1(0.2)$ & $0(0)$ & $0(0)$ \\
\hline $\begin{array}{l}\text { Sekhukune } \\
\text { Facility C }\end{array}$ & 550 & $283(51)$ & $78(14)$ & 361 (66) & $0(0)$ & & $0(0)$ & $1(0.2)$ & $7(1)$ & $16(3)$ & $11(2)$ & $1(0.2)$ & $1(0.2)$ & $1(0.2)$ \\
\hline $\begin{array}{l}\text { Mopani } \\
\text { Facility A }\end{array}$ & 533 & $254(48)$ & $88(77)$ & $342(64)$ & $13(2)$ & $27(5)$ & $0(0)$ & $36(7)$ & $0(0)$ & $28(5)$ & $38(7)$ & $6(1)$ & $11(2)$ & $0(0)$ \\
\hline $\begin{array}{l}\text { Mopani } \\
\text { Facility B }\end{array}$ & 378 & $241(64)$ & $80(21)$ & 321 (85) & $0(0)$ & $0(0)$ & $0(0)$ & $0(0)$ & $0(0)$ & $38(10)$ & $13(3)$ & $3(0.8)$ & $1(0.3)$ & $0(0)$ \\
\hline Capricorn & 696 & $302(43)$ & $186(27)$ & $488(70)$ & $0(0)$ & $18(3)$ & $0(0)$ & $0(0)$ & $0(0)$ & $0(0)$ & $11(2)$ & $4(0.6)$ & $22(3)$ & $10(1)$ \\
\hline Waterberg & 222 & $136(61)$ & $9(4)$ & $145(65)$ & $0(0)$ & $34(15)$ & $2(0.9)$ & $16(7)$ & $12(5)$ & - & - & - & - & - \\
\hline
\end{tabular}

School oral health promotion was recorded in three districts, namely, Mopani, Waterberg and Vhembe. Only Facility B in Mopani recorded a tooth brushing programme in the district (with 135 participating children). Schoolbased dental screenings were conducted in Vhembe $(n=559)$ and Mopani $(n=413)$. The number of school recall visits ranged from one to nine visits. The number of new school visits ranged from four to nine across the three identified districts. It should be noted that most institutions indicated that the school holidays was the reason for the lack of community-based oral health activities during the time of the survey.

Staff perception on oral health service provision Half of the study sample $(n=42,50 \%)$ indicated an opinion of there being insufficient institutional support for oral health care but 18 respondents (21\%) were unsure. Only 34 respondents (42\%) agreed that there were adequate numbers of dental rooms available for oral health service delivery (Table 2). More than half of the study sample $(n=55,66 \%)$ agreed that there were adequate numbers of clinical staff for oral health care. However, all five District Managers did not agree that the number of oral health professionals was sufficient and appropriate $(n=5,100 \%)$. District managers emphasised the shortages in particular categories of oral health professionals, specifically the availability of dental specialists.

Only 34 respondents (42\%) believed that there were sufficient administrative and support staff for effective delivery of oral health services. Less than a quarter of the respondents $(n=19,23 \%)$ indicated that dental resources were adequate and easily available $(n=17,21 \%)$. Similar low responses were obtained $(n=8,10 \%)$ on whether dental equipment was repaired timeously. It was noted that a mere 32 respondents (38\%) believed that staff morale was high while a notable number of respondents $(n=17,20 \%)$ were unsure.

In addition, 37 respondents (44\%) indicated that preventive programmes are integrated into other health activities yet the statistical records on oral health activities fail to reflect this initiative. Respondents also identified possible barriers to the utilisation of oral health services. This is reflected in the following quotations: "People still use home remedies for dental pain; People stay with the disease until it is unbearable and then come for help; Oral health workers do not provide outreach services".

\section{Oral health decision making}

The interview with the Provincial Manager revealed that oral health care challenges included inadequate infrastructure and dental resources, indifferent attitude towards oral health care, coupled with lack of clear oral health representation within different levels of the health system. This deprived oral health staff of leadership, communication and participation in health decision-making. The absence of oral health care policy statements within strategic health plans also contributed to the isolation of oral health services and exclusion from budgetary allocations.

Several themes arose from qualitative analysis. These included lack of policy commitment; no dedicated funding; and poor support for oral health services. The responses of District Managers on the open-ended questions on service delivery in Limpopo Province included: - "Challenges of non-functional dental equipment"; "Health centres were ill equipped; patients were travelling far distances to access services; and "mobile trucks for oral health services were either broken or in a state of disrepair".

The responses recording the perceptions of the $\mathrm{OHCWs}$ on institutional support for oral health care included:"lack of recognition of the oral health providers by health facilities management; no provincial oral health policy existed, and there was no dedicated oral health budget; these circumstances were challenging for procurement for basic consumables, repair and service of equipment." Some of the recommendations for improved oral health service delivery included: "Educate managers of hospital about the importance of oral health. Increase the budget for oral health services. Buy the needed equipment and service them regularly". 


\begin{tabular}{|c|c|c|c|c|c|c|c|}
\hline Statements & $\begin{array}{l}\text { Strongly } \\
\text { agree }\end{array}$ & Agree & Not sure & Disagree & $\begin{array}{l}\text { Strongly } \\
\text { disagree }\end{array}$ & Total (\%) & P-values \\
\hline Sufficient number of dental rooms available & $15(18.3)$ & $19(23.2)$ & $0(0)$ & $20(24.4)$ & $28(34.1)$ & $82(100)$ & 0.14 \\
\hline Sufficient clinical staff available & $14(16.7)$ & $41(48.8)$ & $0(0)$ & $22(26.2)$ & $7(8.3)$ & $84(100)$ & 0.15 \\
\hline $\begin{array}{l}\text { Sufficient support staff available (DA, GA, } \\
\text { Admin staff }\end{array}$ & $8(10)$ & $26(32.1)$ & $1(1.2)$ & $36(44.4)$ & $10(12.3)$ & $81(100)$ & 0.95 \\
\hline Resources are adequate & $3(3.6)$ & $16(19.3)$ & $1(1.2)$ & $34(41)$ & $29(34.9)$ & $83(100)$ & 0.67 \\
\hline $\begin{array}{l}\text { Dental resources are easily obtained when a } \\
\text { requisition is made }\end{array}$ & $4(4.9)$ & $13(16)$ & $1(1.2)$ & $32(39.5)$ & $31(38.3)$ & $81(100)$ & 0.49 \\
\hline All equipment is repaired timeously & $2(2.4)$ & $6(7.3)$ & $0(0)$ & $25(30.1)$ & $49(60)$ & $82(100)$ & 0.24 \\
\hline
\end{tabular}

\section{DISCUSSION}

The results indicate that oral health service delivery in Limpopo Province is very much facility-based and curative driven. The statistical records reveal that dental utilization patterns centre around the relief of pain and sepsis and imply that oral diseases such as dental caries and periodontal disease may be the most prevalent oral conditions treated in the identified health facilities. The limited provision of other oral health services such as restorative care, fissure sealants, scaling and polishing and topical fluoride applications, is a major concern. These findings are consistent with reports from other studies. Ogbebor and Azodo also reported that patients sought dental treatment primarily for the relief of pain and discomfort. ${ }^{9}$ Benoit et al add that oral health services are limited in many underdeveloped countries and that the availability and accessibility of these services are adversely affected by limitations in resources. ${ }^{4}$

Given that the majority of patients are dependent on public oral health services, it is worrisome that the results of this study highlight notable challenges in funding, resource allocation, and support for oral health infrastructure and dental equipment. Bhayat and Cleaton-Jones also indicated that oral health services in South Africa are largely inaccessible to the majority of the population, specifically the unemployed and socioeconomically disadvantaged populations, because of transport costs and user fees for treatment services. ${ }^{14}$ The study findings are further supported by the Limpopo Oral Health 2014-2019 Transformation Plan, ${ }^{13}$ which reports that a Provincial audit conducted in 2008 found almost $70 \%$ of dental equipment required replacement and that oral health service delivery was dominated by extractions (90\%). Only about 5\% of service delivery included preventive care programmes. ${ }^{13}$ This study, in addition, found fragmented and inconsistent statistical data on prevention and promotion care. Community-based oral health activities appear to be centred around school visits and mobile outreach programmes, and the available evidence suggests that these activities are sporadic. Dental screenings formed the core of school-based oral health programmes. These findings are in line with the observation of Singh et al that oral health promotion programmes were uncoordinated, poorly distributed and inadequate for the population of South Africa. ${ }^{17}$

The findings also reveal that oral health care workers were not equitably distributed across the districts in Limpopo. This is supported by Singh et al. who also identified imbalances in the urban-rural distribution of oral health care workers in South Africal. ${ }^{17}$ Petersen advocates that high levels of oral diseases result in greater demand for oral health care workers, equipment, oral health facilities and financial resources. ${ }^{2}$ He notes that the regions with lower levels of oral diseases demand fewer highly trained oral health care workers and more technical equipment but rather require more auxiliary oral health professionals and prevention programs. ${ }^{2,19}$ There is therefore a need to reexamine the oral health skills-mix for the Province and to identify an appropriate staff establishment that can best meet appropriatethe goals of oral health service delivery.

The lack of dedicated budgetary allocations appears to be the main reason for this bleak picture of oral health service delivery in Limpopo Province. The literature suggests that developing countries with low resources invest very little in oral health care and allocate the available resources to provide emergency oral health services for relief of pain. ${ }^{2,5,17}$ Thorpe concurs that oral health programmes are not prioritised in Africa, due to the competing presence of several general health challenges. ${ }^{5}$

\section{Focus on prevention}

There is without doubt, an urgent need for a paradigm shift in the policies of oral health service delivery in Limpopo towards an emphasis on prevention and promotion that extends beyond the current focus on school-based programmes. Given that the majority of extractions were performed on permanent teeth, it can be assumed that dental caries and/or periodontal disease are prevalent across the life cycle. Thus there is a need for oral health promotion strategies to include activities that target individuals and communities in all age groups. Oral health care workers need to identify strategies to address lifestyleinduced risks to oral health, such as increased sugar consumption and smoking. Similarly, programmes should be developed to increase access to additional fluoride uptake, specifically in areas where naturally occurring fluoride in the water is low and there are high levels of dental caries rates..$^{13}$ Oral health decision makers need to build stronger relations with key stakeholders within the various levels of the health system (national, provincial, district and institutional levels) to form collaborative links and partnerships that could best support the oral health agenda. ${ }^{1,17}$ There is an urgent need to identify specific strategies that can translate policy statements on oral health care into implementable programmes that can contribute to positive health outcomes. ${ }^{17}$ Oral health care workers need to be involved in the planning, implementation and evaluation of oral health services to ensure true ownership and accountability to oral service delivery. 


\section{LIMITATIONS OF THE STUDY}

Several constraints were noted in the study. There was limited access to the statistical records. The available records were a reflection of oral health service provision in an identified health institution on a monthly basis at a particular point in time. There were no comparative records to determine trends in service delivery over time and within the identified health institution. Nevertheless these records provide a substantive picture of oral health service delivery in Limpopo.

\section{CONCLUSION}

The results suggest that there is an urgent need for reorientation of oral health service delivery in Limpopo Province with a greater emphasis on prevention and promotion. There is also an urgent need for oral health advocacy within health decision-making across the public health system in Limpopo to ensure that the goals of oral health care are made possible through dedicated policy support and finding.

\section{Conflict of interests: None declared}

\section{Acknowledgements}

We wish to thank the following people for their valuable contribution in the preparation of this paper:

1. Dr Jeffrey Ramalevhana, Department of Health, Limpopo Province, for guidance on data collection and presentation.

2. Mr Abidile Lebotsamang, Botswana, for analysing the data collected from the questionnaires.

3. The Provincial Oral Health Department in Limpopo Province for granting access to the statistical records on oral health services and professionals in Limpopo Province.

\section{References}

1. Singh S. Dental caries in South Africa: implications for oral health planning. South African Journal for Epidemiology. 2011; 26: 259-61.

2. Petersen P. World Health Organization, Geneva: Switzerland International Dental Journal. 2008; 58. 115-21.

3. Hobdell M. Poverty, oral health and human development. J American Dental Association. 2010; 138: 1433-6.

4. Benoit V, Petersen P, Fournet F, et al. Illness-related behaviour and utilization of oral health health services among adult city dwellers in Burkina -Faso: evidence from a house hold survey. BMC Health Service Research. Open Access, 2007; p 1-12.

5. Thorpe S. Oral Health Issues in the African Regions: Current Situation and Future Perspectives. American Dental Education Association. 2006; p 1-8.

6. Oral Health Coordinating Committee (OHCC). (2014). Oral Health Strategic Framework 2014-2017. The United States Public Health Service (USPHS). The U.S. Department of Health and Human Services.

7. Thema LK and Singh S. Integrated primary oral health services in South Africa: The role of the PHC nurse in providing oral examination and education. African Journal for Primary Health Care, Family Medicine. 2013;5(1) ART.\#413.4 pages http://dx.doi.org/10.4102/phcfm.v5i1.413.

8. Van Wyk P.J, van Wyk C. Oral health in South Africa. International Dental Journal. 2004; 54:373-7.

9. OgbeborOG, Azodo CC. Reasons for seeking dental healthcare services in a Nigerian missionary hospital. Sahel Med J [serial online] 2016 [cited 2016 Sep 25]; 19:38-43. Available from: http://www.smjonline.org/text.asp?2016/19/1/38/181901

10. Strategic Planning Committee. Annual Performance Plan 2013/14. Limpopo Province: Department of Health and Social Development, 2015.
11. De Vries J, et al. Caries and fluoride levels in Lebowa. Department of Community Dentistry. Medunsa. 1984.

12. Bhayat A, Cleaton-Jones P. Dental clinic attendance in Soweto, South Africa, before and after the introduction of free primary dental health services. Journal of Community Dentistry and Oral Epidemiology. 2003; 31: 105-10.

13. Transformation Task Committee. Limpopo Oral Health 20142019 Transformation Plan. Limpopo Province: Department of Health and Social Development, 2014. p10.

14. Mann S. Introductory Statistics. 6th ed. Eastern Connecticut State University. 2007: p 6.

15. Bailey K. Methods of Social Research. 2nd Ed. 1982; pp 83-107.

16. Braun V, Clarke V. Using thematic analysis in psychology. Qualitative Research in Psychology. University of Auckland and University of West England. 2006; pp 77-101.

17. Singh S, Myburgh N.G, Lalloo R. Policy analysis of oral health promotion in South Africa. Global Health Promotion. 2010;17(1): 16-24.

18. Petersen P. Continuous improvement of oral health in the 21 century. WHO Global Oral Health Program. The World Oral Health Report. 2003; 31. p 3-23.

19. Monajem S. Integration of primary oral health care into primary health care. The role of Dental Hygienist and the WHO stewardship. International Journal Dent Hygiene. 2006; 4:47-51.

20. Petersen P, Bourgeois D, Bratthall D, Ogawa H. Oral health information system- towards measuring progress in oral health promotion and disease prevention. Bulletin of the World Health Organization. 2005;89 (9): 689-90.

21. Watt R. Oral Health Planning Workshop. National Oral Health Conference. 2006.

22. Lehohla P. Mid-year population estimates by Province. Statistics South Africa. Statistics release. 2010. (P0302). p 4.

23. Sheiham A. Oral Health, General Health and Quality of life. Bulletin of World Health Organisation. 2005; Vol. 83(9).

24. Mahler H. "People". Scientific American. 1980; 143: 63-73.

25. Brink H. Fundamentals for research methodology for health care professionals. 2nd ed. Cape Town. Juda \& Co (Pty) Ltd. 2009.

26. Bowden A, Fox-Rushby J, Nyandieka L, Wanjau J. Methods for pre-testing and piloting surveys. Illustrations from the KENQOL survey of health-related quality of life. Health Policy and Planning. Oxford University Press. 2002; 17 (3):322-30.

27. Presser S, Blair J. Survey pretesting: do different methods produce different results? Sociological Methodology. 1994 24:74-81.

28. Fossey E, Harvey C, McDermott F, Davidson L. Understanding and evaluating qualitative research. Australian and New Zealand Journal of Psychiatry. 2002; 36:717-32.

29. Fisher R. Oral Health Professional's Statistics by Provinces. The Who, What \& Where of HealthCare. Medpages Statistics. 2010; Sep1- 2.Web address: http://www.medpages.co.za.

30. Kwan S, Petersen P, Pine C, Borutta A. Health promoting schools, an opportunity for oral health promotion. Bulletin of the World Health Organisation. 2005. 83(9):677-85.

31. Limpopo Premier's Office. Limpopo Employment, Growth and Development Plan 2009-2014. 2009.

32. District Development, Policy, Planning and Information: North West Province HST (page 91) 